\title{
Interaction of caffeine with the SOS response pathway in Escherichia coli
}

\author{
Alyssa K Whitney and Tiffany L Weir
}

\begin{abstract}
Background: Previous studies have highlighted the antimicrobial activity of caffeine, both individually and in combination with other compounds. A proposed mechanism for caffeine's antimicrobial effects is inhibition of bacterial DNA repair pathways. The current study examines the influence of sub-lethal caffeine levels on the growth and morphology of SOS response pathway mutants of Escherichia coli.

Methods: Growth inhibition after treatment with caffeine and methyl methane sulfonate (MMS), a mutagenic agent, was determined for E. coli mutants lacking key genes in the SOS response pathway. The persistence of caffeine's effects was explored by examining growth and morphology of caffeine and MMS-treated bacterial isolates in the absence of selective pressure.

Results: Caffeine significantly reduced growth of E. coli recA- and uvrA-mutants treated with MMS. However, there was no significant difference in growth between umUC-isolates treated with MMS alone and MMS in combination with caffeine after $48 \mathrm{~h}$ of incubation. When recA-isolates from each treatment group were grown in untreated medium, bacterial isolates that had been exposed to MMS or MMS with caffeine showed increased growth relative to controls and caffeine-treated isolates. Morphologically, recA-isolates that had been treated with caffeine and both caffeine and MMS together had begun to display filamentous growth.

Conclusions: Caffeine treatment further reduced growth of recA- and uvrA-mutants treated with MMS, despite a non-functional SOS response pathway. However, addition of caffeine had very little effect on MMS inhibition of umuCmutants. Thus, growth inhibition of E. coli with caffeine treatment may be driven by caffeine interaction with UmuC, but also appears to induce damage by additional mechanisms as evidenced by the additive effects of caffeine in recAand uvrA-mutants.
\end{abstract}

Keywords: Caffeine, DNA repair, SOS response pathway, Escherichia coli

\section{Background}

Caffeine is derived from plant leaves and is commonly found in consumed beverages such as tea and coffee at concentrations of $0.25-2.0 \%(\mathrm{w} / \mathrm{v})$ [1]. Among the adult population in the United States, daily intake of caffeine is approximately $165 \mathrm{mg} /$ day, largely through coffee consumption [2]. Due to its prevalence in the American diet, interactions between caffeine and pharmaceuticals likely occur, and there is value in exploring the interaction between caffeine and select antibiotics [3]. Previous studies have demonstrated that caffeine has direct

*Correspondence: tiffany.weir@colostate.edu

Department of Food Science and Human Nutrition, Colorado State University, 220 Gifford Building, Fort Collins, CO 80523, USA antimicrobial activity, although reports of the specific inhibitory concentrations vary. Ibrahim et al. noted antimicrobial activity of caffeine against the human enteric pathogen, Escherichia coli $\mathrm{O} 157$ at concentrations as low as $0.5 \%(\mathrm{w} / \mathrm{v})$ - similar in concentration to caffeine levels present in foods. This concentration resulted in slowed growth rate of E. coli $\mathrm{O} 157$ cells and reduced growth overall. However, at lower concentrations, caffeine is only bacteriostatic and $E$. coli growth recovered once the caffeine was removed [1]. Kang et al., reported failure of $E$. coli $\mathrm{K} 12$ strains to grow in concentrations of caffeine as low as $4 \mathrm{mg} / \mathrm{mL}(0.4 \% \mathrm{w} / \mathrm{v})[3]$, but this increased sensitivity may be due to the differences between $E$. coli strains used in these studies. 
Beyond bacteriostatic effects, caffeine synergistically enhances the activity of select antibiotics. Kanamycin activity is increased with the addition of $0.25 \mathrm{mg} / \mathrm{mL}$ $(0.025 \% \mathrm{w} / \mathrm{v})$ caffeine [3]. Kanamycin interacts with the $30 \mathrm{~s}$ subunit of prokaryotic ribosomes, inducing mistranslation of mRNA to protein [4] and is thought to damage DNA base pairs [3]. Thus, a potential target for caffeine activity is through interaction with DNA repair pathways, such as the SOS response pathway. Selby and Sancar observed increased sensitivity of bacterial cells to DNA damaging agents when pre-treated with caffeine [5]. Kang et al. noted that caffeine enhanced the sensitivity of specific mutants (dnaQ, holC, holD and priA) suggesting that caffeine acts by blocking DNA replication and causing double-strand breaks that require recombinatorial repair by $\operatorname{rec} A, \operatorname{rec} B, \operatorname{rec} C$ and others [3]. Interestingly, the synergistic effect does not occur when caffeine is paired with bleomycin or cisplatin, and the activity of ciprofloxacin decreases when paired with caffeine [3]. Synergistic inhibition of bacterial growth in the presence of antibiotics and caffeine is therefore not ubiquitous, but rather depends on the mechanism of action of the antibiotic.

The SOS response pathway is the bacterial DNA repair pathway activated in response to extensive damage to DNA, resulting in halted synthesis [6]. Several studies suggest that mutagen-potentiating effects of caffeine are mediated through interaction with DNA repair mechanisms, such as the SOS response pathway [7-9]. This hypothesis is supported through evidence of caffeine's inhibition on SOS repair proteins in in vitro enzyme assays [10]. In the current study, we examine three of the genes regulated by the SOS pathway: $\operatorname{rec} A$ (recombination repair), umuC (trans-lesion synthesis), and $u v r A$ (nucleotide excision repair) (Fig. 1).

Induction of the SOS response pathway begins when RecA protein, at basal levels in the cell, binds to singlestranded or double-stranded breaks in the DNA, becoming a co-protease that facilitates the degradation of LexA-a transcriptional repressor bound to the SOS box of the bacterial DNA [11]. Destruction of the repressor allows for expression of genes involved in DNA repair, marking the beginning of the SOS response pathway. The three genes of interest in this study are controlled by the SOS box in this fashion. RecA, responsible for the induction of the pathway [10, 12], encodes recombination repair, a mechanism that repairs double-stranded breaks and gaps in the DNA by using a template strand from a homologous DNA molecule [6]. UvrA, with UvrB and UvrC, is involved in nucleotide excision repair, the repair of mismatched nucleotides or dimers. Specifically, the A subunit aids in the delivery of the B subunit to the DNA where, along with $\mathrm{UvrC}$, it removes damaged nucleotides and inserts the correct nucleotide based on the sequence of the complementary strand [6]. A previous study indicates the importance of this pathway in repair of damage induced by mutagenic agents like methyl methanesulfonate (MMS), an alkylating agent that leads to methylation of the DNA and induces single-stranded breaks [12]. UmuC, along with UmuD', activated by RecA, form DNA Polymerase V, the molecule responsible for trans-lesion synthesis. This is generally regarded as the final step in the pathway. After approximately $40 \mathrm{~min}$ of stalled replication, DNA Polymerase V adds random nucleotides

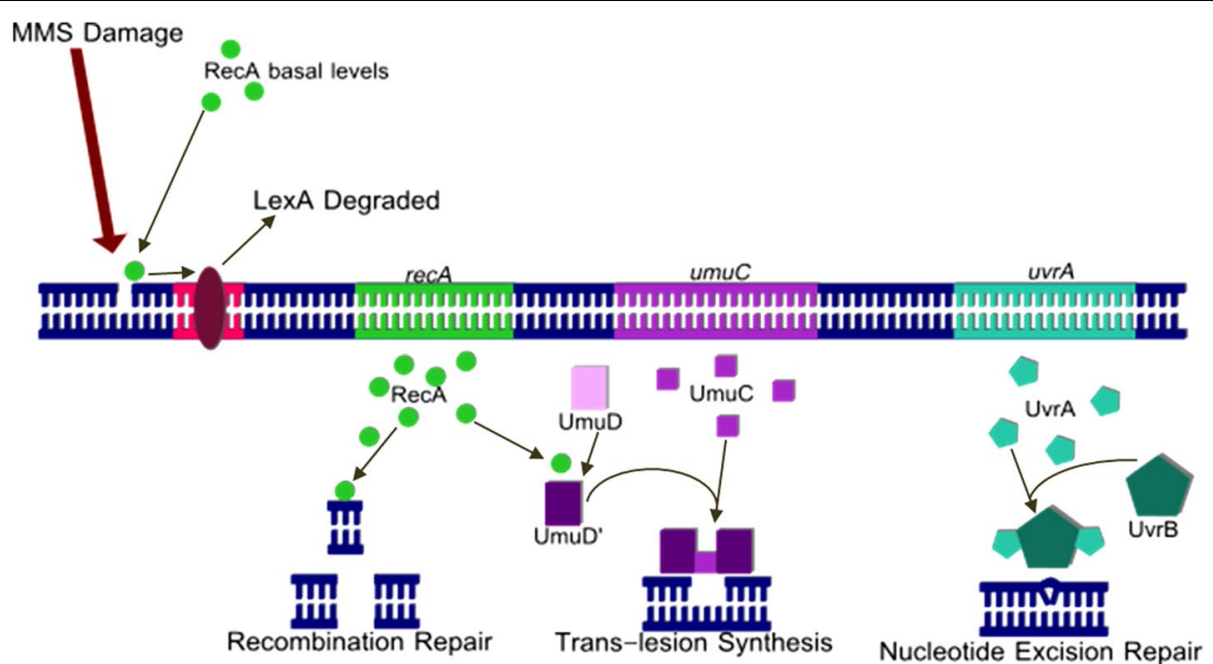

Fig. 1 E. coli SOS response pathway. SOS response pathway in E. coli cells involving recombination repair (recA), trans-lesion synthesis (umuC), and nucleotide excision repair (uvrA). 
to the damaged region of the DNA to allow replication to continue [6]. This highly error-prone mechanism is known to be involved in repair of alkylation damage from MMS [12].

Activity of these three pathways is responsive to caffeine treatment. Recombination repair and trans-lesion synthesis are induced by caffeine [8], but are highly error prone and often introduce mutations to the DNA. Furthermore, the overall growth of cells deficient in RecA is reduced by $8 \mathrm{mM}(0.15 \% \mathrm{w} / \mathrm{v})$ caffeine, an inhibitory dose. In RecA deficient cells, this dose is less than the effective dose needed for inhibition of wild-type cells [13], suggesting caffeine sensitivity may be mediated through the recombination repair pathway. In enzyme assays, $10 \mathrm{mM}(0.19 \% \mathrm{w} / \mathrm{v})$ caffeine has been shown to inhibit the nucleotide excision repair pathway, potentially by interfering with the A subunit of the Uvr complex, as inhibition is greatest when caffeine is added to the reaction prior to the delivery of the $\mathrm{B}$ subunit to the damaged DNA [5]. After further study of this phenomenon, Sandlie et al. hypothesized that, by intercalating into the DNA and competing with the damaged DNA site, caffeine leads to nonspecific binding of the A subunit [7]. Thus, caffeine may be valuable in preventing recovery from mutagenic agents like MMS through interaction with the SOS response pathway, makes caffeine valuable for preventing recovery from mutation by other agents, like MMS [11]. Here we utilize MMS to induce DNA damage and activate RecA, nucleotide excision repair, and trans-lesion synthesis [12] in E. coli cells deficient in specific proteins involved in the SOS response, so we can examine the mechanism of action by caffeine in relation to SOS repair systems. We hypothesize that caffeine directly interferes with the SOS response in E. coli cells. Therefore, in strains with non-functional SOS response proteins, we expect to see no difference of $E$. coli growth between MMS with or without caffeine.

\section{Methods}

\section{Bacterial strains}

E. coli $\mathrm{K}-12$ BW25113 parent strain and single gene deletion mutants umuC-JW1173-1, recA-JW2669-1, and uvrA-JW4019-2 were obtained from the Keio Knockout Collection [14], distributed by The Coli Genetic Stock Center at Yale University. All strains were cultured in Luria-Bertani (LB) growth medium at $37^{\circ} \mathrm{C}$.

\section{Growth inhibition assay}

Bacterial isolates were chosen from LB plates and were then incubated at $37^{\circ} \mathrm{C}$ in LB broth (control and MMS treatments) or LB broth amended with $0.625 \mathrm{mg} / \mathrm{mL}$ $(0.06 \% \mathrm{w} / \mathrm{v})$ caffeine (MMS + caffeine co-treatments) for $24 \mathrm{~h}$ prior to inhibition assays in a $96-$ well plate format.
We demonstrated that this concentration of caffeine $(0.625 \mathrm{mg} / \mathrm{mL})$ was sub-inhibitory in parent $E$. coli strain (Fig. 2), and was lower than active concentrations demonstrated by Ibrahim et al. and Sandlie et al. $[1,6]$. The optical density $\left(\mathrm{OD}_{600}\right)$ of the overnight liquid cultures was measured by spectroscopy on a multi-mode plate reader (BioTek Synergy 2) and diluted in the same growth medium to $\mathrm{OD}_{600}=0.02$ prior to addition to assay plates.

Inhibition assays were conducted in 96-well plates, with each well filled with $100 \mu \mathrm{L}$ of medium- LB broth for MMS alone and the control group, and LB broth amended with caffeine for co-treated wells. Controls were incubated in LB broth without added caffeine. $100 \mu \mathrm{L}$ of $5 \mathrm{mg} / \mathrm{mL}$ MMS was added to the top row of each column in the treatment groups. In the control wells, the MMS was replaced with sterile water. The treatments and water control were diluted in a 1:2 serial dilution down the plate, with a final volume of $100 \mu \mathrm{L}$ in each well. The final concentrations of MMS in the wells were $2.5 \mathrm{mg} / \mathrm{mL}(0.25 \% \mathrm{w} / \mathrm{v}), 1.25 \mathrm{mg} / \mathrm{mL}(0.125 \% \mathrm{w} / \mathrm{v})$, $0.625 \mathrm{mg} / \mathrm{mL}(0.06 \% \mathrm{w} / \mathrm{v}), 0.313 \mathrm{mg} / \mathrm{mL}(0.0313 \% \mathrm{w} / \mathrm{v})$, $0.156 \mathrm{mg} / \mathrm{mL}(0.0156 \% \mathrm{w} / \mathrm{v})$, and $0.078 \mathrm{mg} / \mathrm{mL}(0.0078 \%$ $\mathrm{w} / \mathrm{v})$. The final concentration of $0.625 \mathrm{mg} / \mathrm{mL}$ caffeine remained constant throughout the caffeine treated wells. Assay plates were inoculated with $5 \mu \mathrm{L}$ of diluted bacteria per well. The plates were covered with sealing film and placed into a BioTek reader programmed to incubate with shaking at $37^{\circ} \mathrm{C}$ and take measurements of absorbance at $600 \mathrm{~nm}$ every two hours. After completion of the assay, E. coli recA-cells were isolated from the $1.25 \mathrm{mg} /$ $\mathrm{mL}$ MMS treatment wells (with and without caffeine) and preserved in $75 \%$ glycerol at $-80^{\circ} \mathrm{C}$ for further experiments. The percent change in growth from the control was calculated using the following formula:

$$
\% \text { Change }=\frac{(\text { treatment }- \text { control })}{\text { control }} \times 100
$$

where the control is equal to the average absorbance of the untreated wells and the treatment is equal to the average absorbance of the treatment replicates minus the absorbance of the MMS blank with the corresponding concentration. Each treatment was run in triplicate on a plate and each plate was repeated two times. Error bars were calculated from the standard deviation of the percent change in growth for each duplicate plate.

\section{Determination of treatment effects on growth and morphology of recA-bacterial isolates}

To determine if the treatment conditions had persistent effects on cell growth and morphology, recA-cells that had been cryogenically persevered from control and treatment wells of the growth inhibition assays were grown on LB agar for 24-48 h. Single colonies were 


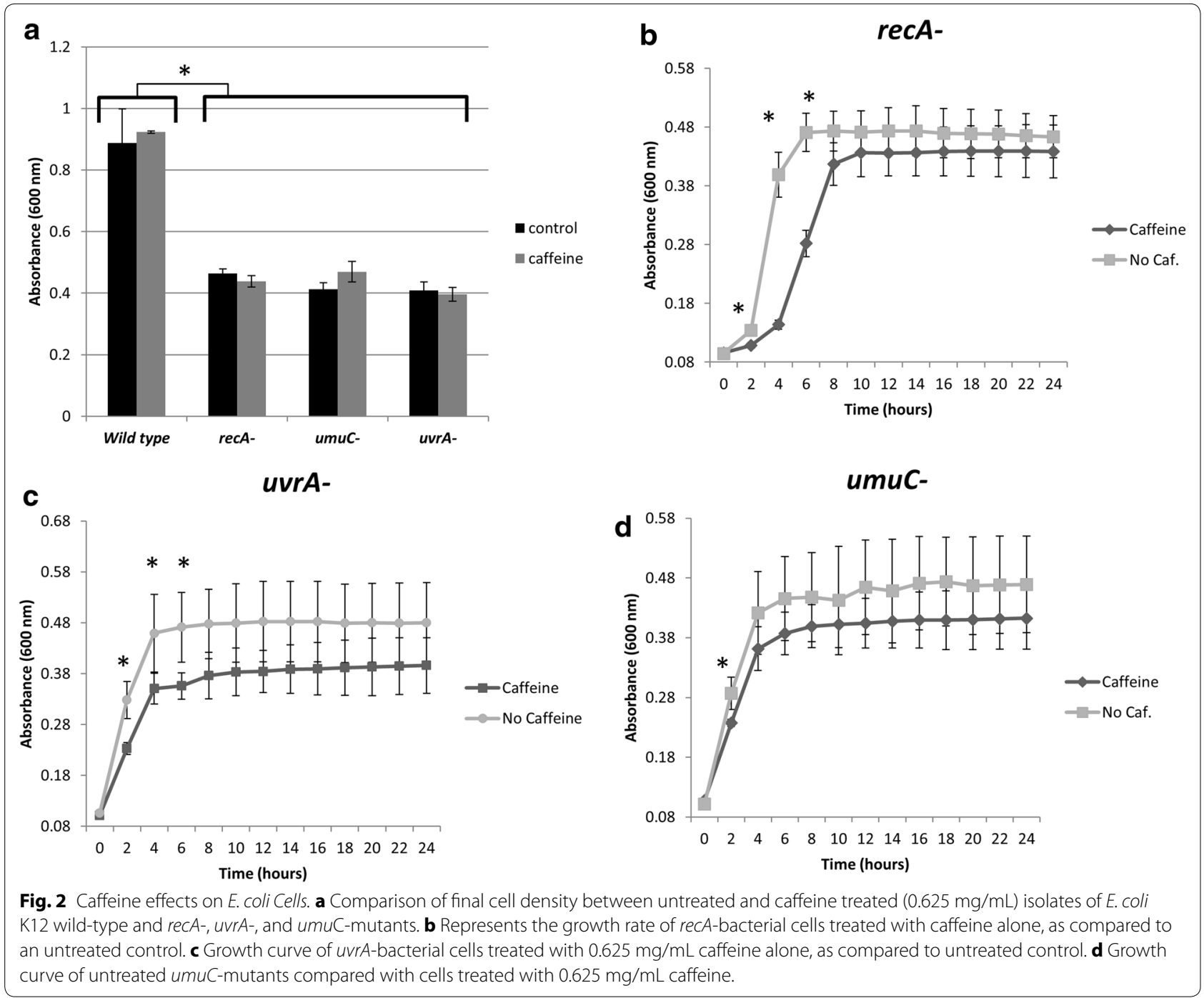

re-suspended in $500 \mu \mathrm{L}$ LB broth and $2 \mu \mathrm{L}$ from each culture were removed and added to $200 \mu \mathrm{L}$ of untreated LB broth in a 96-well plate. The plate was incubated at $37^{\circ} \mathrm{C}$ with slow, continuous shaking and absorbance at $600 \mathrm{~nm}$ was measured every hour for an $8 \mathrm{~h}$ period. Three replicates of each treatment were tested.

Differences in cell morphology between treatment groups were examined by microscopy. As described, isolates of $E$. coli recA-from each treatment condition were removed from cryogenic storage and plated on LB agar for $24 \mathrm{~h}$. Bacteria were suspended in 2-3 drops of water on slides and then dried and heat fixed. Cells were stained with a solution of $200 \mu \mathrm{g} / \mathrm{mL}$ Nile red in acetone and incubated at $37^{\circ} \mathrm{C}$ for $1 \mathrm{~min}$ in the dark and rinsed with $\mathrm{dH}_{2} \mathrm{O}$. Slides were then destained in $70 \% \mathrm{EtOH}$ and allowed to dry overnight. Slides were visualized under oil at 1,000 $\times$ magnification on an Olympus BX3-CB11 microscope.

\section{Statistical analysis}

Student's $T$ tests were performed in Excel to determine significant differences in growth inhibition between MMS and MMS-caffeine treated wells. Growth curve data were analyzed using 2-way ANOVA with post hoc Tukey's test conducted with XL Stat-Pro. A 95\% confidence interval was used, and values of $\mathrm{P}<0.05$ were considered significant.

\section{Results}

\section{Effects of caffeine on E. coli SOS pathway mutants}

To test the effects of caffeine on the SOS pathway, we confirmed that $0.625 \mathrm{mg} / \mathrm{mL}$ of caffeine, which was shown in previous experiments to be sub-inhibitory to several types of bacteria including, E. coli O157 (data not shown), did not inhibit the growth of wild-type $E$. coli K-12 or the mutant strains tested. After $24 \mathrm{~h}$, there were no significant differences in cell density between treated 
and control isolates of wild-type or mutant E. coli; however, SOS mutants displayed significantly lower growth compared to the parent strain (Fig. 2a). This caffeine concentration was also incubated with each of the mutants to determine effects on growth rate (Fig. $2 \mathrm{~b}-\mathrm{d}$ ). The growth rate of $E$. coli recA- and $u v r A$-cells was reduced, but the final cell density by $24 \mathrm{~h}$ was unaffected (Fig. 2b, c). Growth of $u m u C$-isolates was initially delayed, but the differences between the treated and untreated cells resolved by $4 \mathrm{~h}$ and final cell density was not significantly different (Fig. 2d).

\section{Growth inhibition of E. coli SOS pathway mutants co-incubated with caffeine and MMS}

We examined the final cell density of $E$. coli SOS repair mutants after 24 and $48 \mathrm{~h}$ of exposure to MMS or caffeine and MMS combined. There was a significant potentiation of growth inhibition when $E$. coli recA-cells were co-treated with $0.625 \mathrm{mg} / \mathrm{mL}$ caffeine and several concentrations of MMS $(1.25,0.625$, and $0.313 \mathrm{mg} /$ $\mathrm{mL}$ ), compared to treatment with MMS alone at the same concentrations (Fig. 3a, b). This increased inhibition with MMS and caffeine co-treatment was also observed in $u v r A$-cells. After $24 \mathrm{~h}$, cells co-treated with $0.625 \mathrm{mg} / \mathrm{mL}$ caffeine and three concentrations of MMS (0.625, 0.313, and $0.156 \mathrm{mg} / \mathrm{mL})$, showed decreased cell density compared to cells treated with MMS alone (Fig. 3c). Greater inhibition in co-treated cells relative to MMS treated cells persisted at $48 \mathrm{~h}$ with additional cotreatment concentrations ( 1.25 and $0.078 \mathrm{mg} / \mathrm{mL}$ MMS) showing significant separation at this time point (Fig. 3d). Unlike the recA- and $u v r A$-mutants, caffeine had little effect on $u m u C$-cells treated with MMS. There was a small, but significant increase in growth inhibition of

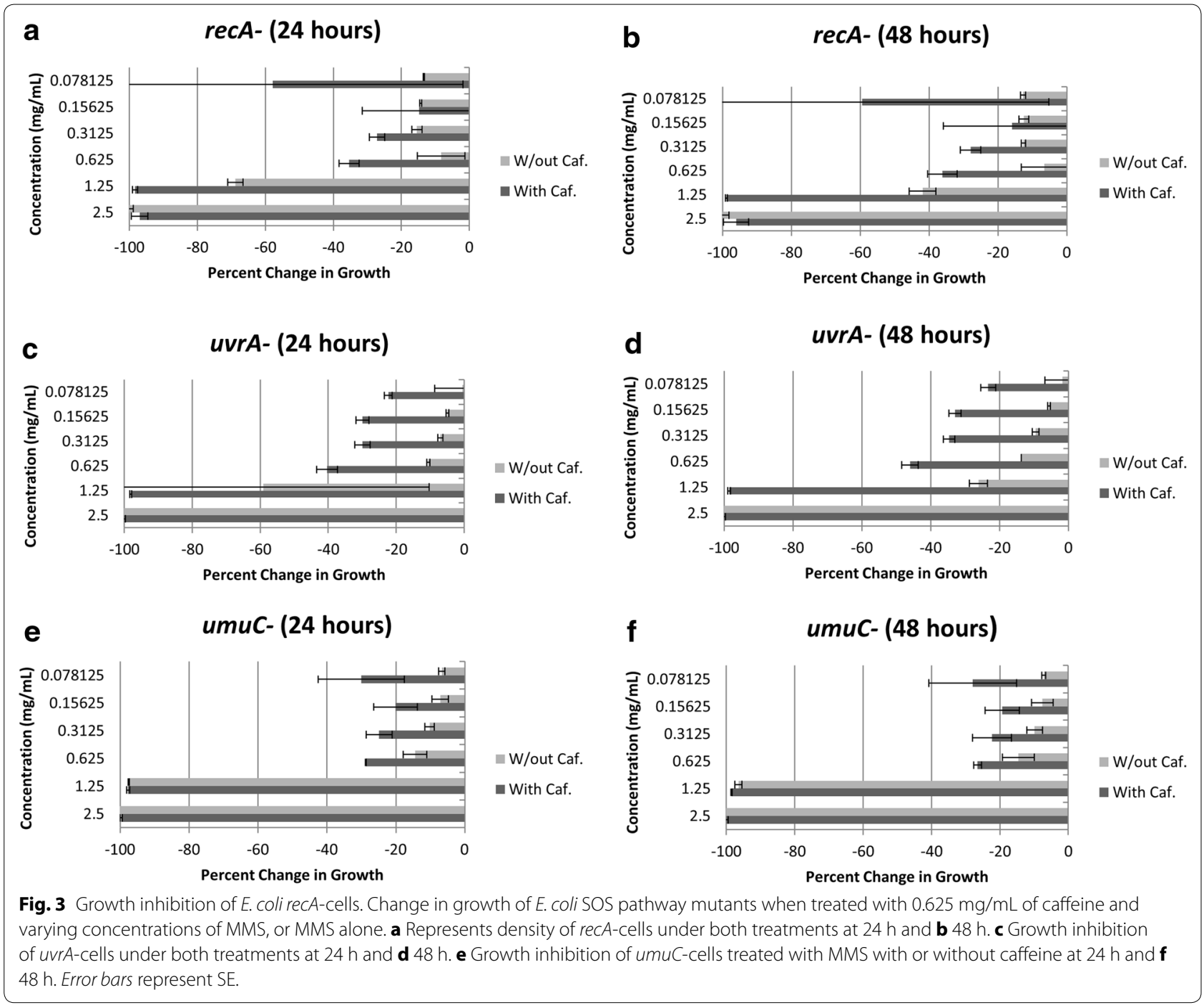


cells co-treated with $0.625 \mathrm{mg} / \mathrm{mL}$ caffeine and at MMS concentrations of 0.625 and $0.313 \mathrm{mg} / \mathrm{mL}$ compared to treatment with the same concentrations of MMS alone at $24 \mathrm{~h}$ (Fig. 3e). However, by $48 \mathrm{~h}$, there was no significant difference in cell density of wells subject to caffeine and MMS co-treatment compared to MMS alone (Fig. 3f). In all mutants there was no additional inhibition by caffeine at the highest concentration of MMS as this concentration alone was sufficient to inhibit bacterial growth.

\section{Persistent effects of caffeine in recA-bacterial isolates}

Because there was evidence of synergistic effects on growth of $E$. coli recA-cells when caffeine pre-treatment was combined with MMS, we explored the persistence of these effects in the absence of selective pressure. Cells isolated from wells treated with $0.625 \mathrm{mg} / \mathrm{mL}$ of caffeine and $1.25 \mathrm{mg} / \mathrm{mL}$ MMS, alone and in combination, and untreated wells were grown in LB liquid medium. Isolates from the MMS treatment groups (both with and without caffeine) displayed a higher growth rate and increased cell density after $8 \mathrm{~h}$ than isolates that had never been exposed to MMS (Fig. 4a). Although the isolates that had previously been exposed to caffeine and MMS grew significantly slower than those isolated from MMS treatment alone, final cell density at $8 \mathrm{~h}$ was not significantly different. Isolates that had been exposed to caffeine alone showed a reduced growth rate compared to control isolates, but by $8 \mathrm{~h}$ showed no significant differences in cell density from controls (Fig. 4a), which was consistent with the growth curves observed in $E$. coli recA-cells when caffeine was present (Fig. 2b).

We also examined cell morphology in E. coli recA-isolates after exposure to the various treatment conditions for evidence of filamentous growth, which is a known $E$. coli stress response [15]. Figure $4 \mathrm{~b}$ represents the morphology of untreated E. coli recA-cells. After treatment with $0.625 \mathrm{mg} / \mathrm{mL}$ caffeine alone (Fig. 4c), the cells appear slightly smaller, and the beginning of filamentous growth is evident. After treatment with $1.25 \mathrm{mg} / \mathrm{mL}$ MMS alone (Fig. 4d), the cells appear unchanged in overall size, but there is some evidence of filamentous growth. After cotreatment with $0.625 \mathrm{mg} / \mathrm{mL}$ caffeine and $1.25 \mathrm{mg} / \mathrm{mL}$ MMS, there is clear evidence of filamentous growth in the E. coli recA-cells (Fig. 4e).

\section{Discussion}

Most studies examining the effects of caffeine on the SOS pathway have not used sub-inhibitory caffeine concentrations, as was done in the current study $(0.06 \%$ caffeine $w / v)$. Therefore, it is difficult to compare the effects on $E$. coli growth that we observed with those previously reported. This study is among the first to demonstrate a reduction in growth rate due to caffeine exposure, but without effects on final cell density achieved as cells entered stationary phase. In the current study, caffeine significantly potentiated the activity of MMS when added as a pretreatment to $r e c A$ - and $u v r A$-mutants. The synergistic interaction seen with co-treatment suggests that caffeine does not inhibit $E$. coli cell growth through interaction with RecA (recombination repair) or UvrA (nucleotide excision repair), two important proteins in the SOS response pathway. Obana et al. reported a failure to significantly reduce SOS functioning with caffeine treatment and noted no difference in SOS activity level with caffeinated and decaffeinated coffee [10]; a result that was consistent with the lack of direct influence observed here. Although our data indicate that caffeine does not interact with RecA or UvrA, there are synergistic interactions between caffeine and MMS, suggesting further study of caffeine's inhibitory mechanisms are warranted as there is potential value for caffeine as an antibiotic adjuvant.

Caffeine may affect cell growth by inhibiting UmuC and subsequently, DNA Polymerase V and trans-lesion synthesis. When added alone, caffeine had almost no effect on the growth rate of $u m u C$-cells compared to the other mutants tested (Fig. 2d). Likewise, we observed little significant difference between treatment with MMS alone and co-treatment with MMS and $0.625 \mathrm{mg} / \mathrm{mL}$ caffeine after $24 \mathrm{~h}$ and no significant difference after $48 \mathrm{~h}$. In a knockout $E$. coli strain where no UmuC is produced, there would be no expected difference in growth between MMS and caffeine/MMS co-treatment. Kim and Levin indicated possible interaction between caffeine and $\mathrm{UmuC}$ in their 1990 study [8], but this topic has been largely unstudied in the intervening time, and further research is required to fully discern the effect of caffeine on UmuC.

Finally, we examined the growth and cellular morphology of $E$. coli recA-cells isolated from assay treatments in the absence of selective pressure to explore the persistence of caffeine's effects. Surprisingly, the cells that had been isolated from MMS and caffeine/MMS cotreatments had a higher growth rate and final cell density compared to untreated cells and those treated only with caffeine (Fig. 4a). This response is likely due to activation of an RpoS-mediated stress response following MMS exposure and cryogenic storage of the cells. This is a commonly triggered stress response in E. coli and related bacteria which results in rapid accumulation of the alternative sigma factor RpoS, and activation of approximately 500 genes that render cells more resistant to generalized stress conditions [16]. Interestingly, caffeine treatment alone did not result in the same accelerated growth when stress was removed, but isolates previously exposed to caffeine behaved similar to when caffeine was present in the growth medium, indicating that caffeine exposure 

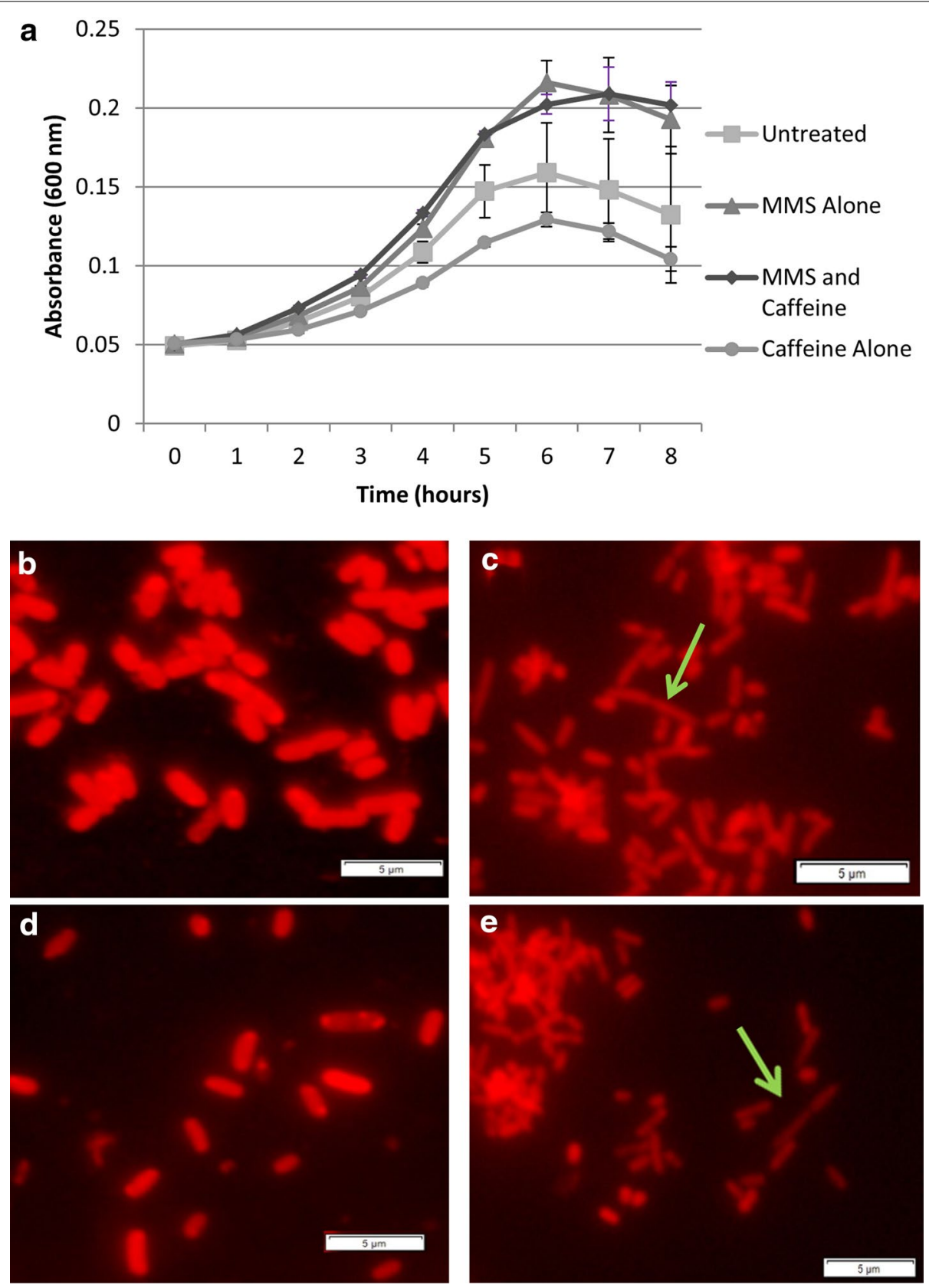

Fig. 4 Persistence of caffeine effects on recA-cells. a Growth of E. coli JW2669-1 (recA-) when treated with $1.25 \mathrm{mg} / \mathrm{mL} \mathrm{MMS}, 0.625 \mathrm{mg} / \mathrm{mL}$ caffeine, and MMS and caffeine co-treatment, in comparison with the growth of untreated cells. Morphology of E. coli recA-cells following inhibition assay. Treatment groups are no treatment $(\mathbf{b})$, caffeine alone $(\mathbf{c}), \mathrm{MMS}$ alone $(\mathbf{d})$, and MMS and caffeine combined treatment (e). Arrows indicate cells displaying filamentous growth. Cells were observed at $\times 1,000$ magnification. Pictures scales are $5 \mu \mathrm{m}$.

caused persistent damage. When we examined these isolates under a microscope, we also observed some filamentous growth in caffeine treated cells. Filamentous growth is a known $E$. coli stress response initiated by DNA damage and activation of SOS responses [15] and allows the cells to continue proliferating at the same rate, although they do not fully divide. Thus, it is likely that caffeine is independently causing damage to the DNA and triggering filamentous growth.

In addition to direct interaction with SOS pathway proteins, several other mechanisms have been proposed to explain caffeine's inhibitory effects on bacterial cell growth. These include inhibition of protein synthesis and interference with ATP binding [17]. There is also 
a report of direct interaction with MMS, potentially through dimer formation [18]. However, there are few conclusive studies investigating these effects. Intercalation of caffeine in DNA is also believed to be responsible for the observed inhibition of E. coli. Caffeine is shown to be a DNA intercalating agent, largely due to similarity in structure to purine nucleotides, and may lead to non-specific binding of repair proteins in the cell $[3,5,13]$, rather than directly interacting with the proteins themselves. Intercalation may also lead to double-stranded breaks in the DNA and frameshift mutations. Furthermore, the increased stress of intercalation by caffeine, in addition to alkylation stress from MMS, could result in observed synergistic interactions and filamentous growth, making the cells more vulnerable to further damage under selective pressure.

\section{Conclusions}

Caffeine has existing medical relevance as an adjuvant in many over-the-counter painkillers [19]. Previous studies have indicated synergistic interaction of caffeine with kanamycin [3] and DNA damaging agents [5]. Identifying the cellular targets of caffeine helps determine which antibiotics would be most effective in combination, as not all antibiotics interact with caffeine in a synergistic manner [3]. We determined that inhibitory activity of caffeine against E. coli $\mathrm{K} 12$ strains is probably not due to interaction with RecA and UvrA proteins, but may occur through interaction with $\mathrm{UmuC}$ and the inhibition of trans-lesion synthesis. Furthermore, observed synergistic interactions of MMS and caffeine may be due to caffeine intercalation in addition to alkylation stress of MMS to bacterial DNA, unrepairable by trans-lesion synthesis, the final step of the SOS response pathway. This DNA damage leads to filamentous growth of $E$. coli cells, allowing the bacteria to continue proliferation but without full cell division. Filamentous growth makes the bacteria more vulnerable to further damage by the MMS and caffeine, because the lack of septa between cells facilitates the diffusion of small molecules. Reduction of E. coli growth by caffeine in a synergistic fashion lends support toward the use of caffeine as an antibiotic adjuvant.

\section{Abbreviations \\ W/v: weight/volume; MMS: methylmethane sulfonate; DIC: differential interfer- ence contrast.}

\section{Authors' contributions}

AW conceived of the study, participated in its design, carried out experiments, participated in analysis of data, and drafted the manuscript. TW participated in design of the study, performed the statistical analysis, participated in analysis of data, and helped to draft the manuscript. Both authors read and approved the final manuscript.

\section{Acknowledgements}

We would like to thank Dr. Elizabeth Ryan for her support and manuscript comments and Dr. Kim Cox-York and Yuren Wei for microscopy assistance. Funding was provided by the American Society for Microbiology Undergraduate Research Fellowship (ASM-URF), the Colorado State University College of Health and Human Sciences and the Colorado State University Honors Department.

\section{Compliance with ethical guidelines}

\section{Competing interests}

The authors declare that they have no competing interests.

Received: 22 May 2015 Accepted: 29 July 2015

Published online: 18 August 2015

\section{References}

1. Ibrahim SA, Salameh MM, Phetsomphou S, Yang H, Seo CW (2006) Application of caffeine, 1,3,7-trimethylxanthine, to control Escherichia coli O157:H7. Food Chem 99:645-650

2. Mitchell DC, Knight CA, Hockenberry J, Teplansky R, Hartman TJ (2014) Beverage caffeine intakes in the US. Food Chem Toxicol 63:136-142

3. Kang TM, Yuan J, Nguyen A, Becket E, Yang H, Miller JH (2012) The aminoglycoside antibiotic kanamycin damages DNA bases in Escherichia coli: caffeine potentiates the DNA-damaging effects of kanamycin while suppressing cell killing by ciprofloxacin in escherichia coli and bacillus anthracis. Antimicrob Agents Ch 56:3216

4. Misumi M, Tanaka N (1980) Mechanism of inhibition of translocation by kanamycin and viomycin: a comparative study with fusidic acid. Biochem Biophys Res Commun 92:647-654

5. Selby CP, Sancar A (1990) Molecular mechanisms of DNA repair inhibition by caffeine. P Natl Acad Sci 87:3522-3525

6. Willey JM, Sherwood LM, Woolverton CJ (2011) DNA repair. In: Prescott's microbiology, 8th edn, Chap no. 14.3. McGraw-Hill, New York, pp 371-374

7. Sandlie I, Lossius I, Sjastad K, Kleppe K (1983) Mechanism of caffeine-induced inhibition of DNA synthesis in Escherichia coli. FEBS Lett 151:237-242

8. Kim J, Levin RE (1990) Influence of caffeine on the induction of SOS function recA and umuC by mitomycin C in Escherichia coli. Microbios 64:185-195

9. Almeida AAP, Farah A, Silva DAM, Nunan EA, Glória MBA (2006) Antibacterial activity of coffee extracts and selected coffee chemical compounds against enterobacteria. J Agr Food Chem 54:8738-8743

10. Obana H, Nakamura S, Tanaka R (1986) Suppressive effects of coffee on the SOS responses induced by UV and chemical mutagens. Mutat Res 175:47-50

11. Janion C (2008) Inducible SOS response system of DNA repair and mutagenesis in Escherichia coli. Int J Biol Sci 4:338-344

12. Grzesiuk E (1998) The role of mutation frequency decline and SOS repair systems in methyl methanesulfonate mutagenesis. Acta Biochim Pol 45(2):523-533

13. Grigg GW (1972) Effects of coumarin, pyronin Y, 6,9-dimethyl 2-methylthiopurine and caffeine on excision repair and recombination repair in Escherichia coli. J Gen Microbiol 70:221-230

14. Baba T, Ara T, Hasegawa M, Takai Y, Okumura Y, Baba M et al (2006) Construction of Escherichia coli K-12 in-frame, single-gene knockout mutants: the Keio collection. Mol Syst Biol 2. doi:10.1038/msb4100050

15. Dash SS, Gummadi SN (2008) Inhibitory effect of caffeine on growth of various bacterial strains. Res J Microbiol 3(6):457-465

16. Battesti A, Majdalani N, Gottesman S (2011) The RpoS-mediated general stress response in Escherichia coli. Annu Rev Microbiol 65:189-213

17. Sandlie I, Solberg K, Kleppe K (1980) The effect of caffeine on cell growth and metabolism of thymidine in Escherichia coli. Mutat Res 73:29-41

18. Banerjee S, Chaudhuri S, Maity AK, Saha P, Pal SK (2014) Role of caffeine in DNA recognition of a potential food-carcinogen benzo[a]pyrene and UVA induced DNA damage. J Mol Recognit 27:510-520

19. Derry CJ, Derry S, Moore RA (2014) Caffeine as an analgesic adjuvant for acute pain in adults (Review). Cochrane DB Syst Rev 2. doi:10.1002/14651858.CD009281.pub3 